\title{
Plasma Homocysteine Is Associated with Increased Oxidative Stress and Antioxidant Enzyme Activity in Welders
}

\author{
Hung-Hsin Liu, ${ }^{1}$ Tung-Sheng Shih, ${ }^{2}$ Hsin-Ru Huang, ${ }^{3}$ Shih-Chien Huang, \\ Lien-Hsiung Lee, ${ }^{5}$ and Yi-Chia Huang ${ }^{6}$ \\ ${ }^{1}$ Department of Occupational Medicine, School of Occupational Safety and Health, Chung Shan Medical University, \\ Chung Shan Medical University Hospital, Taichung 40201, Taiwan \\ ${ }^{2}$ Graduate Institute of Environmental Health, College of Public Health, China Medical University and Hospital, \\ Taichung 40402, Taiwan \\ ${ }^{3}$ Department of Nutrition, Mennonite Christian Hospital, Shoufeng Branch, Hualien 974, Taiwan \\ ${ }^{4}$ Department of Health and Nutrition Biotechnology, Asia University, Taichung 41354, Taiwan \\ ${ }^{5}$ Institute of Occupational Safety and Health, Council of Labor Affairs, Executive Yuan, Taipei 22143, Taiwan \\ ${ }^{6}$ Department of Nutrition, School of Nutrition, Chung Shan Medical University, Chung Shan Medical University Hospital, \\ Taichung 40201, Taiwan
}

Correspondence should be addressed to Yi-Chia Huang; ych@csmu.edu.tw

Received 1 July 2013; Accepted 6 August 2013

Academic Editors: P. P. Egeghy, A. Ojajärvi, and J. Thrasher

Copyright (C) 2013 Hung-Hsin Liu et al. This is an open access article distributed under the Creative Commons Attribution License, which permits unrestricted use, distribution, and reproduction in any medium, provided the original work is properly cited.

The purpose of this study was to examine the association of vitamin $\mathrm{B}_{6}$ status and plasma homocysteine with oxidative stress and antioxidant capacities in welders. Workers were divided into either the welding exposure group $(n=57)$ or the nonexposure controls $(n=42)$ based on whether they were employed as welders. There were no significant differences in vitamin $\mathrm{B}_{6}$ status and plasma homocysteine concentration between the welding exposure group and the nonexposure controls. The welding exposure group had significantly higher levels of oxidized low-density lipoprotein cholesterol and lower erythrocyte glutathione concentration and superoxide dismutase (SOD) activities when compared to nonexposure controls. Plasma pyridoxal $5^{\prime}$-phosphate concentration did not correlate with oxidative stress indicators or antioxidant capacities in either group. However, plasma homocysteine significantly correlated with total antioxidant capacity (TAC) (partial $r_{s}=-0.34, P<0.05$ ) and erythrocyte SOD activities (partial $r_{s}=0.29, P<0.05$ ) after adjusting for potential confounders in the welding exposure group. In the welding exposure group, adequate vitamin $\mathrm{B}_{6}$ status was not associated with oxidative stress or antioxidant capacities. However, elevated plasma homocysteine seemed to be a major contributing factor to antioxidant capacities (TAC and erythrocyte SOD activities) in welders.

\section{Introduction}

Welders constitute a large work force in Taiwan and worldwide. Welding is a process of joining metals by melting and fusing, and this process generates fumes. The fumes contain many metals and toxic gases [1], which produce free radicals and cause lipid peroxidation [2-4] and further cause a variety of adverse health effects. Welders exposed to these metals and toxic gases during the welding process have been shown to be associated with increased oxidative stress and alterations in antioxidants or antioxidant capacities when compared to controls [5-9]. Fortunately, the human body has antioxidant enzyme and nutrient systems that protect it against free radical attacks. The main antioxidant enzymes responsible for controlling oxygen free radicals are superoxide dismutase (SOD), catalase, and glutathione-dependent enzymes [i.e., glutathione peroxidase $(\mathrm{GPx})$, glutathione reductase, and glutathione $S$-transferase (GST)] [10]. In addition to antioxidant enzymes, major antioxidant nutrients include vitamin A, $\mathrm{C}$, and $\mathrm{E}$. Recently, the potent antioxidant ability of vitamin $\mathrm{B}_{6}$ has been recognized [11-18].

Pyridoxal $5^{\prime}$-phosphate (PLP), the physiologically active coenzyme form of vitamin $\mathrm{B}_{6}$, may play a crucial role in antioxidant mechanism. Although the exact antioxidant 
mechanism has not been confirmed yet, PLP may directly scavenge radicals and inhibit lipid peroxidation [11, 16, 1921] or may indirectly play an antioxidant role through serving as coenzymes in the glutathione antioxidant defense system. Plasma PLP serves as a coenzyme in the transsulfuration pathway of homocysteine to cysteine. Cysteine synthesized by this pathway is an important contributor to glutathione synthesis. It would then be reasonable to hypothesize that greater oxidative stress might be associated with lower vitamin $\mathrm{B}_{6}$ status, a higher homocysteine concentration, and an impaired glutathione-dependent antioxidant defense system [22-24].

Welders are particularly susceptible to fume exposure during the welding process. In this high oxidative stress environment, the utilization and metabolic turnover of vitamin $\mathrm{B}_{6}$ increase, and this lowers the body's pool of the vitamin. Although the effects of welding fume exposures on oxidative stress and antioxidant capacities have been studies in welders, no data on the associations of vitamin $\mathrm{B}_{6}$ status and homocysteine with oxidative stress and antioxidant capacities have been reported. The purpose of this study was to examine the associations of vitamin $\mathrm{B}_{6}$ status (plasma and erythrocyte PLP) and plasma homocysteine with oxidative stress and antioxidant capacities in welders.

\section{Materials and Methods}

2.1. Participants. This cross-sectional study enrolled workers from the industry (Changhua, Taiwan), which offers a complete line of innovative fitness products in central Taiwan. This study was approved by the Institutional Review Board of Chung Shan Medical University hospital (Taichung, Taiwan), and each participant signed the informed consent form.

Welders were recruited into the welding exposure group if they were older than 20 years and had been employed full time for at least 3 months. Welders did not work in a specific area but were involved in various welding-related processes, including formulating, mixing, loading, and welding application and were exposed to variable levels of fumes. The control participants were white-collar office workers employed in the same company who were not exposed to welding fumes, and they were assigned into the nonexposure control group. Exclusion criteria were pregnancy or lactation, illness, history of gastrointestinal disorder, cardiovascular disease, liver and renal diseases, diabetes, cancer, alcoholism, or other metabolic disease.

All subjects' age, smoking status and drinking habits, welding exposure time, and duration of employment were recorded. Body weight and height were measured; the body mass index (BMI; $\mathrm{kg} / \mathrm{m}^{2}$ ) was then calculated. Fasting venous blood specimens were collected in vacutainer tubes (Becton Dickinson, Rutherford, NJ, USA) containing EDTA as an anticoagulant or without anticoagulant and were centrifuged (2500 rpm, $15 \mathrm{~min}$ ) to separate serum/plasma and red blood cells then analyzed immediately or stored frozen $\left(-80^{\circ} \mathrm{C}\right)$ until analysis. Spot urine samples were collected from each participant.

2.2. Biochemical Analyses. Hematological entities (i.e., albumin, hemoglobin, creatinine, triglycerides, total cholesterol, low-density lipoprotein cholesterol (LDL), and high-density lipoprotein cholesterol) were measured by using an automated biochemical analyzer. Plasma and erythrocyte PLP were determined by high performance liquid chromatography (HPLC) according to a method described by Talwar et al. [25]. The inter- and intra-assay variabilities were $4.38 \%$ $(n=11)$ and $1.23 \%(n=5)$ for plasma PLP and $7.16 \%$ $(n=12)$ and $3.33 \%(n=5)$ for erythrocyte PLP, respectively. A plasma PLP level $\geq 20 \mathrm{nmol} / \mathrm{L}$ has been suggested as an indicator of adequate vitamin $\mathrm{B}_{6}$ status $[26,27]$. Plasma homocysteine was measured by using HPLC with a modified method as described previously [28]. Hyperhomocysteinemia was defined as a plasma homocysteine concentration $\geq 15 \mu \mathrm{mol} / \mathrm{L}$ [29]. The inter- and intra-assay variabilities of plasma homocysteine were $4.03 \%(n=8)$ and $1.72 \%(n=5)$, respectively. Plasma lipid peroxidation was measured as the levels of malondialdehyde (MDA) according to a modified method as described by Lapenna et al. [30]. The MDA level was measured at an excitation wavelength of $515 \mathrm{~nm}$ and an emission wavelength of $555 \mathrm{~nm}$ using a fluorescence spectrophotometer. Oxidized LDL (ox-LDL) was measured with ox-LDL ELISA kit (Mercodia AB, Uppsala, Sweden). Among the methodologies used to evaluate total antioxidant capacity (TAC), the most widely used colorimetric method for serum and plasma samples are $2^{\prime}-2^{\prime}$-azinobis-3-ethylbenzothiazoline-6-sulfonate-based methods. Therefore, TAC was measured according to a method described by Erel [31], who developed a novel colorimetric and automated direct assay. Reduced glutathione concentration in erythrocyte was measured by using glutathione assay kit (Cayman Chemical Company, Michigan, USA). GPx catalyzes the reduction of hydroperoxides, including hydrogen peroxide, by reducing glutathione and functions to protect the cell from oxidative damage [32]. Erythrocyte GPx levels were measured by using GPx assay kit (Cayman Chemical Company, Ann Arbor, MI, USA). GST is a ubiquitous multifunctional enzyme, which plays a key role in cellular detoxification [32]. Erythrocyte GST was determined by using GST assay kit (Cayman Chemical Company, Ann Arbor, MI, USA). SOD catalyzes the dismutation of superoxide into oxygen and hydrogen peroxide, after which the peroxide can be destroyed by catalase and GPx. SOD is an important antioxidant defense in nearly all cells exposed to oxygen. Erythrocyte SOD was determined by using SOD assay kit (Cayman Chemical Company, Ann Arbor, MI, USA). Urinary creatinine and 8-oxo-7,8-dihydro-2' -deoxyguanosine (8-OHdG) levels were measured. Urinary $8-\mathrm{OHdG}$ concentration is a biomarker of oxidative DNA damage and repair and was determined using a competitive enzyme-linked immunoassay (Genox Corporation, Baltimore, MD, USA).

2.3. Statistical Analysis. Data were analyzed using the SAS statistical software (version 9.2, Statistical Analysis System Institute, Inc., Cary, NC, USA). A sample size of 47 subjects would allow detecting at least as well significantly correlated $(r=0.4)$ between plasma PLP or homocysteine and antioxidant enzyme activities with $80 \%$ statistical power and a twosided $\alpha$ level of less than 0.05 . A Kolmogorov-Smirnov test was performed to test the normal distribution. Differences 
in participants' demographic characteristics and biochemical values were compared for significance using student $t$-test or Mann-Whitney Rank Sum test between groups. Chisquare test was used for the analysis of categorical variables. Spearman correlation coefficient $\left(r_{s}\right)$ was used to analyze the association of vitamin $\mathrm{B}_{6}$ status and plasma homocysteine with oxidative stress indicators and antioxidant capacities in the welding exposure group and nonexposure controls. Spearman partial correlation coefficient (partial $r_{s}$ ) was further used to analyze the association of vitamin $B_{6}$ status and plasma homocysteine with oxidative stress indicators and antioxidant capacities in the welding exposure group and nonexposure controls after adjusting for age, gender, serum albumin and creatinine, smoking and drinking status, and duration of employment. Results were considered statistically significant at $P<0.05$. Values presented in the text are means standard deviation (SD).

\section{Results}

Characteristics of participants are shown in Table 1. Ninetynine subjects completed this study. Subjects' ages ranged from 20 to 61 years, with a mean age of 33.4 years. Fiftyseven welders were classified into the welding exposure group, while there were 42 white-collar office workers in the nonexposure control group. There were no significant differences in age, weight, height, BMI, serum triglycerides, total cholesterol, and LDL concentrations between the two groups. Welders had significantly higher levels of serum hemoglobin and creatinine and higher percentage of smoking and drinking habits when compared with the controls.

Table 2 shows subjects' vitamin $\mathrm{B}_{6}$ status, homocysteine, oxidative stress, and antioxidant enzyme activities during the study. Welders and nonexposure controls had similar vitamin $B_{6}$ status (i.e., plasma and erythrocyte PLP), and none of welders or controls had deficient vitamin $B_{6}$ status (plasma PLP $<20 \mathrm{nmol} / \mathrm{L}$ ). No significant differences in plasma homocysteine, MDA and TAC levels, erythrocyte GPx and GST activities and urinary 8-OHdG concentration were observed between the two groups. However, welders had significantly higher ox-LDL levels and lower erythrocyte glutathione concentrations and erythrocyte SOD activities than did nonexposure controls.

Plasma PLP strongly correlated with erythrocyte PLP in exposure welders $\left(r_{s}=0.68, P<0.001\right)$ and nonexposure controls $\left(r_{s}=0.57, P<0.001\right)$. The correlations between the mean of vitamin $\mathrm{B}_{6}$ status, plasma homocysteine, oxidative stress, and antioxidant capacities in welders and nonexposure controls are shown in Table 3. Plasma and erythrocyte PLP concentrations did not correlate with oxidative stress indicators (i.e., MDA, ox-LDL, and 8-OHdG) and antioxidant capacities (TAC, SOD, GPx, and GST activities) in welders. However, plasma homocysteine significantly positively correlated with the MDA level and erythrocyte SOD activity in welders. We further adjusted potential confounders including age, gender, serum albumin and creatinine, smoking and drinking status, and duration of employment which might affect oxidative stress and antioxidant capacities; plasma homocysteine still significantly positively correlated with erythrocyte SOD activity and negatively correlated with TAC in welders (Table 4).

\section{Discussion}

It has been reported that welders exposed to welding fumes have higher oxidative stress and lower antioxidant capacities than that of controls [5-9]. Our welders had significantly higher ox-LDL concentrations and lower erythrocyte SOD activities when compared to controls. The finding indicates that welders are under greater oxidative stress and lower antioxidant capacity during welding process. In addition to oxidative stress indicators in plasma, we also measured urinary 8-OHdG concentration. Nuernberg et al. [9] observed that welders had a significantly higher rise in urinary 8OHdG excretion when comparing preshift with postshift change. Urinary 8-OHdG concentration might normalize back to baseline by 24 hours from the start of the exposure [9]. Since we only collected urine sample from each subject at preshift time, this might explain why we did not observe the difference in urinary $8-\mathrm{OHdG}$ concentration between welders and controls.

In the past decades, vitamin $\mathrm{B}_{6}$ status and oxidative stress responses were mostly studied in animal models; very little data in humans have been reported. Recently, the association between higher oxidative stress and lower vitamin $\mathrm{B}_{6}$ status has been observed in older individuals [18], which might suggest the potent antioxidant ability of vitamin $B_{6}$ in humans. Unfortunately, we did not observe the significant association of vitamin $B_{6}$ status with oxidative stress indicators and antioxidant capacities in our subjects. Since none of our welders had inadequate vitamin $\mathrm{B}_{6}$ status (plasma PLP concentration $<20 \mathrm{nmol} / \mathrm{L}$ ), other potential risk factors might affect welders' oxidative stress and antioxidant capacities. Although the exact role which the vitamin $\mathrm{B}_{6}$ compounds play as antioxidants is not clear yet, as long as welders maintain an adequate plasma PLP concentration, their vitamin $B_{6}$ status is unlikely to affect their oxidative stress or antioxidant capacities.

In the transsulfuration pathway of homocysteine metabolism, it requires plasma PLP as a coenzyme. Plasma homocysteine concentration, therefore, might be associated with vitamin $\mathrm{B}_{6}$ status. In addition to vitamin $\mathrm{B}_{6}$ status, plasma homocysteine concentration was measured in our subjects. Higher oxidative stress due to higher homocysteine concentration through homocysteine oxidation has been observed [33-35]. Elevated plasma homocysteine concentration may induce excessive production of reactive oxygen species and impair the glutathione-related antioxidant defense system thus leading to greater oxidative stress and lower antioxidant enzymatic activities [22, 36-38]. Our welders with higher homocysteine concentration had increased MDA level and erythrocyte SOD activities when potential confounders were not adjusted. Since smoking may be an important cause of oxidative stress and antioxidant capacities and this is known to be potentiated by exposure to fumes/toxic gases in the work place, smoking was forced into all models as 
TABle 1: Demographic and clinical characteristics of participants.

\begin{tabular}{|c|c|c|}
\hline Characteristics & $\begin{array}{l}\text { Welding exposure } \\
\quad(n=57)\end{array}$ & $\begin{array}{c}\text { Nonexposure controls } \\
(n=42)\end{array}$ \\
\hline Age (y) & $33.29 \pm 10.40$ & $33.67 \pm 7.46$ \\
\hline Gender (male/female) & $46 / 11^{\mathrm{a}}$ & $9 / 33^{\mathrm{b}}$ \\
\hline Height $(\mathrm{cm})$ & $165.15 \pm 8.19$ & $162.96 \pm 7.49$ \\
\hline Weight $(\mathrm{kg})$ & $61.94 \pm 16.13$ & $57.78 \pm 12.31$ \\
\hline Body mass index $\left(\mathrm{kg} / \mathrm{m}^{2}\right)$ & $22.64 \pm 5.69$ & $21.55 \pm 3.23$ \\
\hline Duration of employment (yr) & $1.99 \pm 2.03^{\mathrm{a}}$ & $3.64 \pm 3.83^{\mathrm{b}}$ \\
\hline Welding exposure time $(\mathrm{hr} / \mathrm{d})$ & $7.54 \pm 3.14$ & - \\
\hline Serum albumin $(\mathrm{g} / \mathrm{dL})$ & $4.61 \pm 0.24^{\mathrm{a}}$ & $4.51 \pm 0.23^{\mathrm{b}}$ \\
\hline Serum hemoglobin (g/dL) & $15.20 \pm 1.22^{\mathrm{a}}$ & $13.88 \pm 1.51^{b}$ \\
\hline Serum creatinine $(\mathrm{mg} / \mathrm{dL})$ & $0.92 \pm 0.16^{\mathrm{a}}$ & $0.81 \pm 0.16^{\mathrm{b}}$ \\
\hline \multicolumn{3}{|l|}{ Lipid profiles } \\
\hline Triglycerides (mg/dL) & $86.58 \pm 55.91$ & $72.07 \pm 36.17$ \\
\hline Total cholesterol (mg/dL) & $167.60 \pm 31.12$ & $176.17 \pm 28.02$ \\
\hline High-density lipoprotein (mg/dL) & $60.18 \pm 12.97^{\mathrm{a}}$ & $67.69 \pm 14.54^{\mathrm{b}}$ \\
\hline Low-density lipoprotein (mg/dL) & $101.70 \pm 29.14$ & $102.95 \pm 23.94$ \\
\hline Smoking $(n, \%)$ & $23(40.35 \%)^{\mathrm{a}}$ & $1(2.38 \%)^{\mathrm{b}}$ \\
\hline Drinking $(n, \%)$ & $6(10.53 \%)^{\mathrm{a}}$ & $1(2.38 \%)^{b}$ \\
\hline
\end{tabular}

Values are means \pm SD.

Values with different superscript letter are significantly different between two groups; $P<0.05$.

TABLE 2: Vitamin $\mathrm{B}_{6}$ status, oxidative stress indicators, glutathione, and antioxidant capacity.

\begin{tabular}{|c|c|c|}
\hline Indicators & $\begin{array}{l}\text { Welding exposure } \\
\quad(n=57)\end{array}$ & $\begin{array}{c}\text { Nonexposure controls } \\
(n=42)\end{array}$ \\
\hline \multicolumn{3}{|l|}{ Vitamin $\mathrm{B}_{6}$ status } \\
\hline Plasma PLP (nmol/L) & $75.48 \pm 72.23$ & $71.16 \pm 91.77$ \\
\hline$<20 \mathrm{nmol} / \mathrm{L}(\%)$ & 0 & 0 \\
\hline Erythrocyte PLP (pmol/g Hb) & $178.36 \pm 191.65$ & $238.29 \pm 462.87$ \\
\hline Plasma homocysteine $(\mu \mathrm{mol} / \mathrm{L})$ & $12.13 \pm 4.14$ & $12.78 \pm 4.75$ \\
\hline$\geq 15 \mu \mathrm{mol} / \mathrm{L}(n, \%)$ & $11(19.30 \%)$ & $9(21.43 \%)$ \\
\hline \multicolumn{3}{|l|}{ Oxidative stress indicators } \\
\hline Malondialdehyde $(\mu \mathrm{M})$ & $0.61 \pm 0.13$ & $0.62 \pm 0.11$ \\
\hline Oxidized low-density lipoprotein (mU/L) & $30329.74 \pm 7507.95^{\mathrm{a}}$ & $27521.15 \pm 5891.29^{\mathrm{b}}$ \\
\hline 8-oxo-7,8-dihydro-2' -deoxyguanosine (ng/mg creatinine) & $2.93 \pm 1.21$ & $3.03 \pm 1.47$ \\
\hline \multicolumn{3}{|l|}{ Antioxidant capacities } \\
\hline Total antioxidant capacity $(\mu \mathrm{mol} / \mathrm{L})$ & $4278.05 \pm 322.82$ & $4280.41 \pm 246.07$ \\
\hline Erythrocyte glutathione $(\mu \mathrm{mol} / \mathrm{g} \mathrm{Hb})$ & $0.65 \pm 0.29^{\mathrm{a}}$ & $0.73 \pm 0.38^{\mathrm{b}}$ \\
\hline Erythrocyte SOD (U/g Hb) & $8461.28 \pm 3202.72^{\mathrm{a}}$ & $13391.24 \pm 4729.43^{\mathrm{b}}$ \\
\hline Erythrocyte GPx (nmol/min/g Hb) & $61858.44 \pm 15727.25$ & $59021.55 \pm 16498.69$ \\
\hline Erythrocyte GST (nmol/min/g Hb) & $10306.87 \pm 6537.18$ & $10943.85 \pm 4201.24$ \\
\hline
\end{tabular}

Values are means \pm SD. PLP: pyridoxal $5^{\prime}$-phosphate; Hb: hemoglobin; SOD: superoxide dismutase; GPx: glutathione peroxidase; GST: glutathione $S$ transferase.

Values with different superscript letter are significantly different between two groups; $P<0.05$.

a likely confounder. Our welders with higher homocysteine concentration were more likely to have lower TAC and higher erythrocyte SOD activity after potential confounders were adjusted. However, elevated homocysteine concentration has been found to be associated with decreased erythrocyte
SOD activities in patients with cardiovascular heart diseases [39]. In a similar vein, Wilcken et al. [40] observed a strikingly positive relationship between excellular SOD and homocysteine in patients with homocystinuria. In agreement with the results of previous studies, elevated homocysteine 


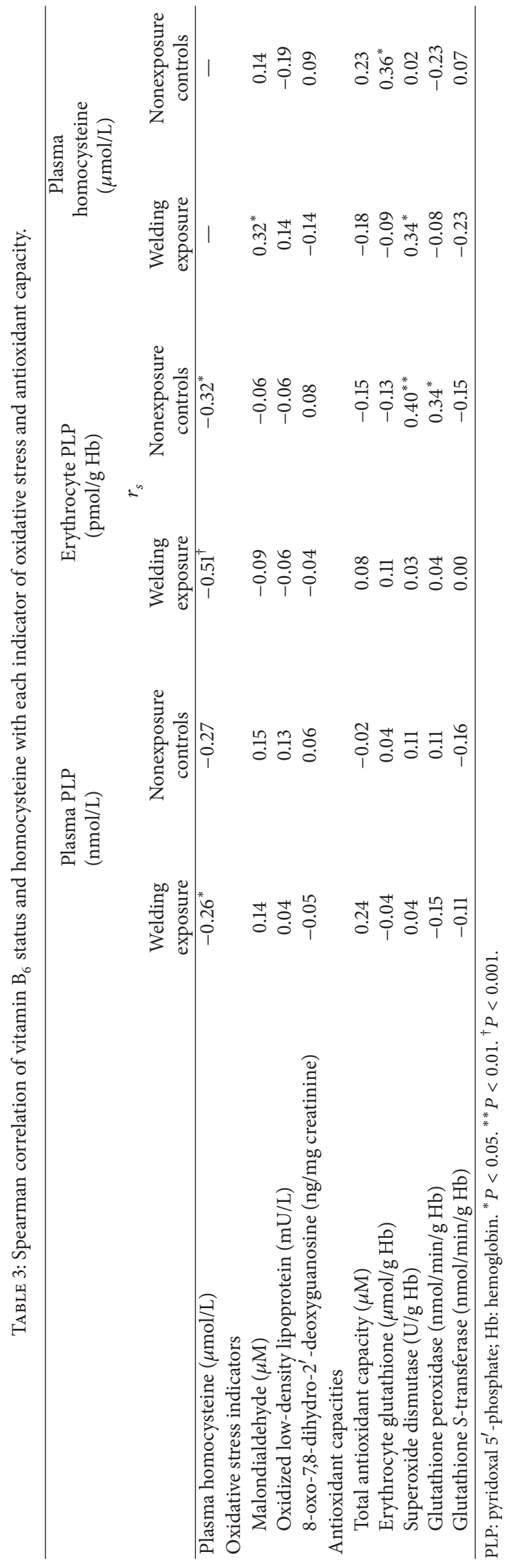




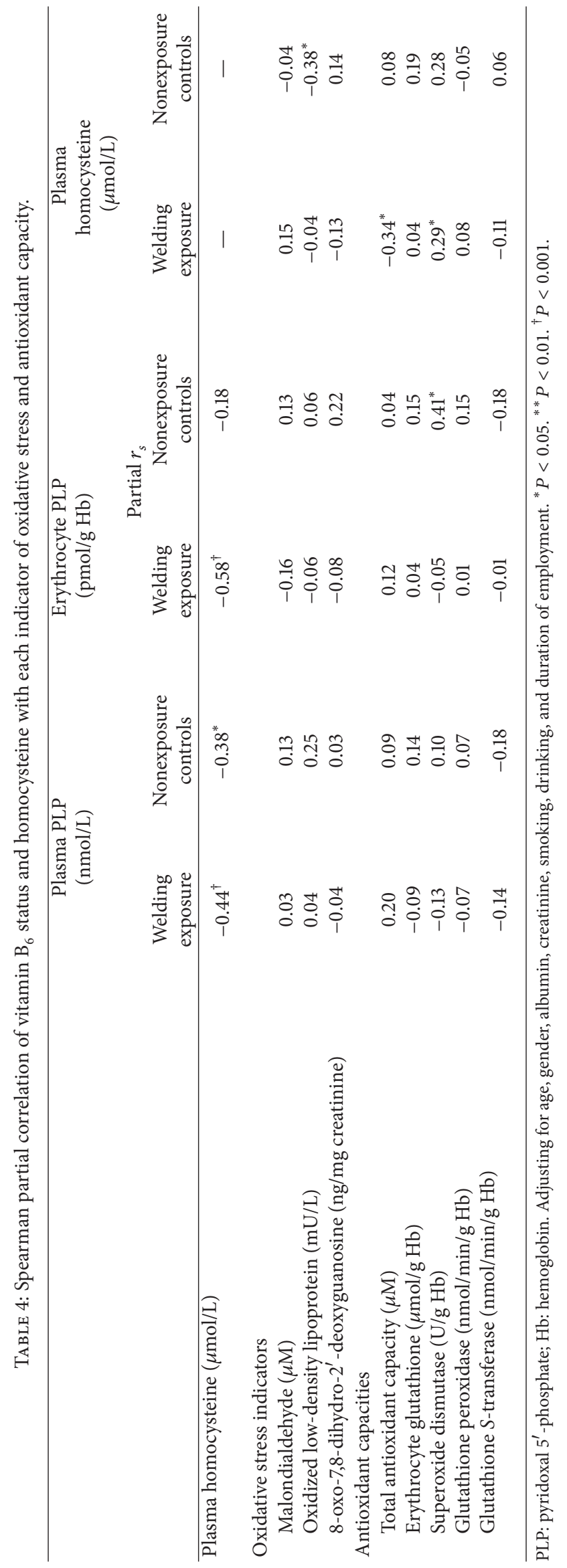


concentration may cause the release of heparan sulfate-bound extracellular SOD into the blood [41] and thus constitute a protective mechanism with the effect of combating oxidative stress [40]. This would explain why our welders simultaneously had higher homocysteine concentration and increased SOD activity. Since we have observed that our welders with higher homocysteine concentration had lower TAC status, we could not rule out the possibility that welders with higher homocysteine concentration might have lower SOD activity if their welding exposure lasts for a longer period of time. It should be pointed out that this study had a crosssectional design, so we could only observe the relationship between homocysteine and SOD activity at one point in time. Therefore, it was not possible to discriminate the short-term and long-term effects of elevated homocysteine concentration on antioxidant enzymatic activities in welders.

There were some limitations in this study. Although we calculated the sample size to meet the statistical power criteria, a larger sample size might be needed to increase the significance of the associations between vitamin $\mathrm{B}_{6}$ and oxidative stress indicators and antioxidant capacities. The other limitation was that this was a cross-sectional design study, so the long-term associations of vitamin $\mathrm{B}_{6}$ and homocysteine with oxidative stress and antioxidant capacities in welders could not be assessed.

\section{Conclusion}

To the best of our knowledge, the present study is the first to show the associations of vitamin $\mathrm{B}_{6}$ status and homocysteine with oxidative stress indicators and antioxidant capacities in welders. The data herein indicate that, among welders, adequate vitamin $\mathrm{B}_{6}$ status was not associated with oxidative stress or antioxidant capacities. In addition to vitamin $\mathrm{B}_{6}$ status, elevated plasma homocysteine seemed to be a major contributing factor in relation to decreased TAC and increased erythrocyte SOD activity in welders. Further research into the long-term association of vitamin $\mathrm{B}_{6}$ and homocysteine concentration with oxidative stress and antioxidant enzymatic activities during welding exposure is warranted.

\section{Conflict of Interests}

All authors have no conflict of interests.

\section{Acknowledgments}

This study was supported by National Science Council, Taiwan (NSC101-2320-B-040-016-MY3) and Council of Labor Affairs, Taiwan. The authors would like to express their sincere appreciation to the subjects for their participation in this trial.

\section{References}

[1] J. M. Antonini, "Health effects of welding," Critical Reviews in Toxicology, vol. 33, no. 1, pp. 61-103, 2003.
[2] K. Furuno, T. Suetsugu, and N. Sugihara, "Effects of metal ions on lipid peroxidation in cultured rat hepatocytes loaded with $\alpha$ linolenic acid," Journal of Toxicology and Environmental Health A, vol. 48, no. 2, pp. 121-129, 1996.

[3] S.-J. Yiin and T.-H. Lin, "Effects of metallic antioxidants on cadmium-catalyzed peroxidation of arachidonic acid," Annals of Clinical and Laboratory Science, vol. 28, no. 1, pp. 43-50, 1998.

[4] X. Shi, A. Chiu, C. T. Chen, B. Halliwell, V. Castranova, and V. Vallyathan, "Reduction of chromium(VI) and its relationship to carcinogenesis," Journal of Toxicology and Environmental Health $B$, vol. 2, no. 1, pp. 87-104, 1999.

[5] M. Stepniewski, E. Kolarzyk, A. Pietrzycka, M. Kitlinski, J. Helbin, and K. Brzyszczan, "Antioxidant enzymes and pulmonary function in steel mill welders," International Journal of Occupational Medicine and Environmental Health, vol. 16, no. 1, pp. 41-47, 2003.

[6] G. J. Li, L.-L. Zhang, L. Lu, P. Wu, and W. Zheng, "Occupational exposure to welding fume among welders: alterations of manganese, iron, zinc, copper, and lead in body fluids and the oxidative stress status," Journal of Occupational and Environmental Medicine, vol. 46, no. 3, pp. 241-248, 2004.

[7] F. Fidan, M. Ünlü, T. Köken et al., "Oxidant-antioxidant status and pulmonary function in welding workers," Journal of Occupational Health, vol. 47, pp. 286-292, 2005.

[8] G. H. Sung, Y. Kim, M. L. Kashon, D. L. Pack, V. Castranova, and V. Vallyathan, "Correlates of oxidative stress and freeradical activity in serum from asymptomatic shipyard welders," American Journal of Respiratory and Critical Care Medicine, vol. 172, no. 12, pp. 1541-1548, 2005.

[9] A. M. Nuernberg, P. D. Boyce, J. M. Cavallari, S. C. Fang, E. A. Eisen, and D. C. Christiani, "Urinary 8-isoprostane and 8OHdG concentrations in boilermakers with welding exposure," Journal of Occupational and Environmental Medicine, vol. 50, no. 2, pp. 182-189, 2008.

[10] N. I. Krinsky, "Mechanism of action of biological antioxidants," Proceedings of the Society for Experimental Biology and Medicine, vol. 200, no. 2, pp. 248-254, 1992.

[11] P. Bilski, M. Y. Li, M. Ehrenshaft, M. E. Daub, and C. F. Chignell, "Vitamin $\mathrm{B}_{6}$ (pyridoxine) and its derivatives are efficient singlet oxygen quenchers and potential fungal antioxidants," Photochem Photobiol, vol. 71, pp. 129-1134, 2000.

[12] P. Stocker, J.-F. Lesgards, N. Vidal, F. Chalier, and M. Prost, "ESR study of a biological assay on whole blood: antioxidant efficiency of various vitamins," Biochimica et Biophysica Acta, vol. 1621, no. 1, pp. 1-8, 2003.

[13] H. Chen and L. Xiong, "Pyridoxine is required for postembryonic root development and tolerance to osmotic and oxidative stresses," Plant Journal, vol. 44, no. 3, pp. 396-408, 2005.

[14] S. A. Denslow, A. A. Walls, and M. E. Daub, "Regulation of biosynthetic genes and antioxidant properties of vitamin $\mathrm{B}_{6}$ vitamers during plant defense responses," Physiological and Molecular Plant Pathology, vol. 66, no. 6, pp. 244-255, 2005.

[15] E. Y. Choi and Y. O. Cho, "Effect of vitamin $B_{6}$ deficiency on antioxidative status in rats with exercise-induced oxidative stress," Nutrition Research and Practice, vol. 3, pp. 208-211, 2009.

[16] M. M. Mahfouz, S. Q. Zhou, and F. A. Kummerow, "Vitamin B compounds are capable of reducing the superoxide radical and lipid peroxide levels induced by $\mathrm{H}_{2} \mathrm{O}_{2}$ in vascular endothelial cells in culture," International Journal for Vitamin and Nutrition Research, vol. 79, no. 4, pp. 218-229, 2009. 
[17] M. Keles, B. Al, K. Gumustekin et al., "Antioxidative status and lipid peroxidation in kidney tissue of rats fed with vitamin $\mathrm{B}_{6}$ deficient diet," Renal Failure, vol. 32, no. 5, pp. 618-622, 2010.

[18] J. Shen, C.-Q. Lai, J. Mattei, J. M. Ordovas, and K. L. Tucker, "Association of vitamin B-6 status with inflammation, oxidative stress, and chronic inflammatory conditions: the Boston Puerto Rican Health Study," American Journal of Clinical Nutrition, vol. 91, no. 2, pp. 337-342, 2010.

[19] M. Ehrenshaft, P. Bilski, M. Li, C. F. Chignell, and M. E. Daub, "A highly conserved sequence is a novel gene involved in de novo vitamin $\mathrm{B}_{6}$ biosynthesis," Proceedings of the National Academy of Sciences of the United States of America, vol. 96, no. 16, pp. 9374-9378, 1999.

[20] B. K. Ohta and C. S. Foote, "Characterization of endoperoxide and hydroperoxide intermediates in the reaction of pyridoxine with singlet oxygen," Journal of the American Chemical Society, vol. 124, no. 41, pp. 12064-12065, 2002.

[21] K. Kannan and S. K. Jain, "Effect of vitamin $B_{6}$ on oxygen radicals, mitochondrial membrane potential, and lipid peroxidation in $\mathrm{H}_{2} \mathrm{O}_{2}$-treated U937 monocytes," Free Radical Biology and Medicine, vol. 36, no. 4, pp. 423-428, 2004.

[22] R.-F. S. Huang, Y.-C. Hsu, H.-L. Lin, and F. L. Yang, "Folate depletion and elevated plasma homocysteine promote oxidative stress in rat livers," Journal of Nutrition, vol. 131, no. 1, pp. 33-38, 2001.

[23] S.-I. Komatsu, H. Watanabe, T. Oka, H. Tsuge, and N. Kato, "Dietary vitamin B6 suppresses colon tumorigenesis, 8-hydroxyguanosine, 4-hydroxynonenal, and inducible nitric oxide synthase protein in azoxymethane-treated mice," Journal of Nutritional Science and Vitaminology, vol. 48, no. 1, pp. 65-68, 2002.

[24] S. J. James, P. Cutler, S. Melnyk et al., "Metabolic biomarkers of increased oxidative stress and impaired methylation capacity in children with autism," American Journal of Clinical Nutrition, vol. 80, no. 6, pp. 1611-1617, 2004.

[25] D. Talwar, T. Quasim, D. C. McMillan, J. Kinsella, C. Williamson, and D. S. J. O'Reilly, "Pyridoxal phosphate decreases in plasma but not erythrocytes during systemic inflammatory response," Clinical Chemistry, vol. 49, no. 3, pp. 515518, 2003.

[26] A. Lui, L. Lumeng, G. R. Aronoff, and T.-K. Li, "Relationship between body store of vitamin $\mathrm{B}_{6}$ and plasma pyridoxal-P clearance: metabolic balance studies in humans," The Journal of Laboratory and Clinical Medicine, vol. 106, no. 5, pp. 491-497, 1985.

[27] Food and Nutrition Board, Institute of Medicine, Dietary Reference Intakes. Thiamin, Riboflavin, Niacin, Vitamin B-6, Folate, Vitamin B-12, Pantothenic Acid, Biotin, and Choline, National Academy Press, Washington, DC, USA, 1998.

[28] A. Araki and Y. Sako, "Determination of free and total homocysteine in human plasma by high-performance liquid chromatography with fluorescence detection," Journal of Chromatography, vol. 422, pp. 43-52, 1987.

[29] D. W. Jacobsen, "Determinants of hyperhomocysteinemia: a matter of nature and nurture," The American journal of clinical nutrition, vol. 64, no. 4, pp. 641-642, 1996.

[30] D. Lapenna, G. Ciofani, S. D. Pierdomenico, M. A. Giamberardino, and F. Cuccurullo, "Reaction conditions affecting the relationship between thiobarbituric acid reactivity and lipid peroxides in human plasma," Free Radical Biology and Medicine, vol. 31, no. 3, pp. 331-335, 2001.
[31] O. Erel, "A novel automated direct measurement method for total antioxidant capacity using a new generation, more stable ABTS radical cation," Clinical Biochemistry, vol. 37, no. 4, pp. 277-285, 2004.

[32] J. D. Hayes and L. I. McLellan, "Glutathione and glutathionedependent enzymes represent a co-ordinately regulated defence against oxidative stress," Free Radical Research, vol. 31, no. 4, pp. 273-300, 1999.

[33] G. Davì, G. di Minno, A. Coppola et al., "Oxidative stress and platelet activation in homozygous homocystinuria," Circulation, vol. 104, no. 10, pp. 1124-1128, 2001.

[34] L. L. Wu and J. T. Wu, "Hyperhomocysteinemia is a risk factor for cancer and a new potential tumor marker," Clinica Chimica Acta, vol. 322, no. 1-2, pp. 21-28, 2002.

[35] M. G. Signorello, G. L. Viviani, U. Armani et al., "Homocysteine, reactive oxygen species and nitric oxide in type 2 diabetes mellitus," Thrombosis Research, vol. 120, no. 4, pp. 607-613, 2007.

[36] G. Starkebaum and J. M. Harlan, "Endothelial cell injury due to copper-catalyzed hydrogen peroxide generation from homocysteine," Journal of Clinical Investigation, vol. 77, no. 4, pp. 1370-1376, 1986.

[37] E. Menegola, M. L. Broccia, M. Prati, R. Ricolfi, and E. Giavini, "Glutathione status in diabetes-induced embryopathies," Biology of the Neonate, vol. 69, no. 5, pp. 293-297, 1996.

[38] E. Nishio and Y. Watanabe, "Homocysteine as a modulator of platelet-derived growth factor action in vascular smooth muscle cells: a possible role for hydrogen peroxide," British Journal of Pharmacology, vol. 122, no. 2, pp. 269-274, 1997.

[39] M. Kerkeni, F. Added, M. B. Farhat, A. Miled, F. Trivin, and K. Maaroufi, "Hyperhomocysteinaemia and parameters of antioxidative defence in Tunisian patients with coronary heart disease," Annals of Clinical Biochemistry, vol. 45, no. 2, pp. 193198, 2008.

[40] D. E. L. Wilcken, X. L. Wang, T. Adachi et al., "Relationship between homocysteine and superoxide dismutase in homocystinuria: possible relevance to cardiovascular risk," Arteriosclerosis, Thrombosis, and Vascular Biology, vol. 20, no. 5, pp. 1199-1202, 2000.

[41] S.-I. Nihei, H. Tasaki, K. Yamashita et al., "Hyperhomocysteinemia is associated with human coronary atherosclerosis through the reduction of the ratio of endothelium-bound to basal extracellular superoxide dismutase," Circulation Journal, vol. 68 , no. 9, pp. 822-828, 2004. 


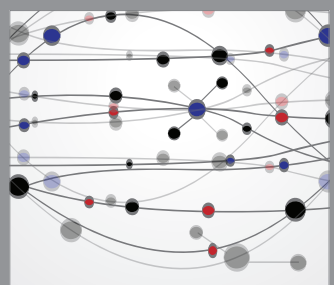

The Scientific World Journal
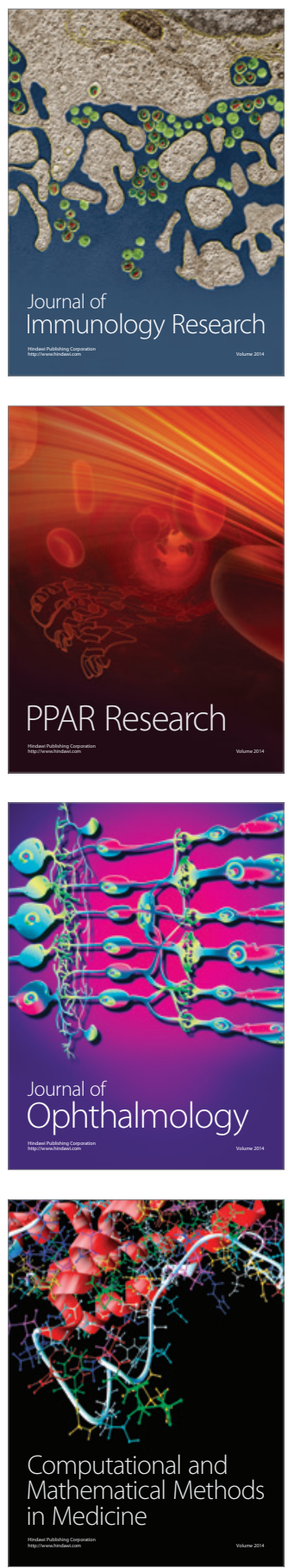

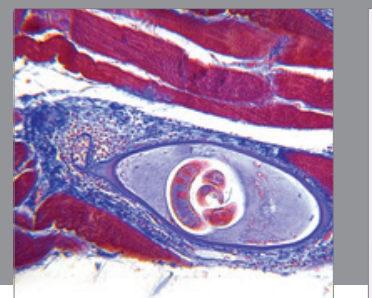

Gastroenterology

Research and Practice
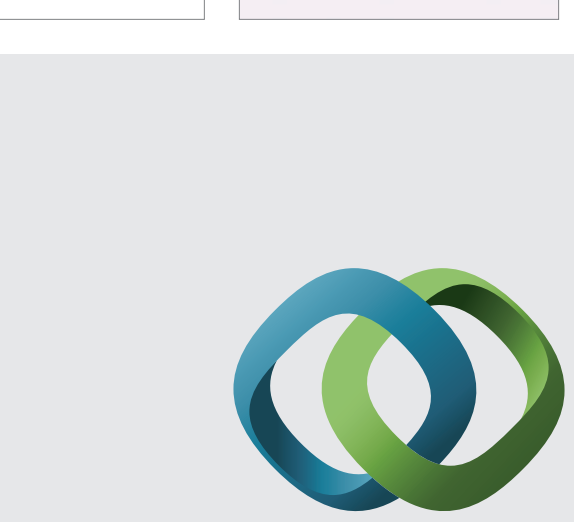

\section{Hindawi}

Submit your manuscripts at

http://www.hindawi.com
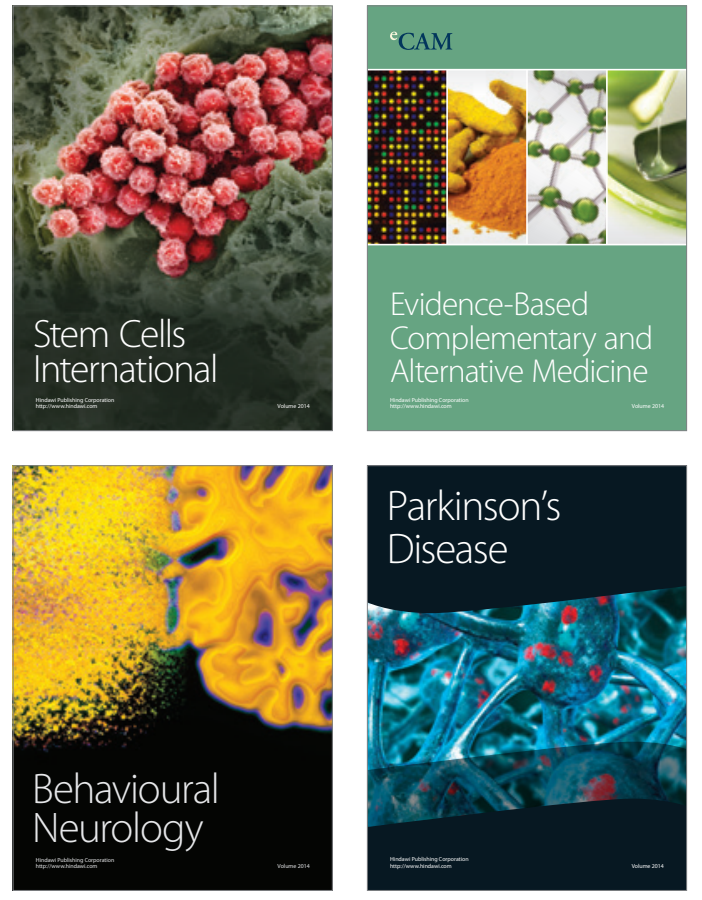
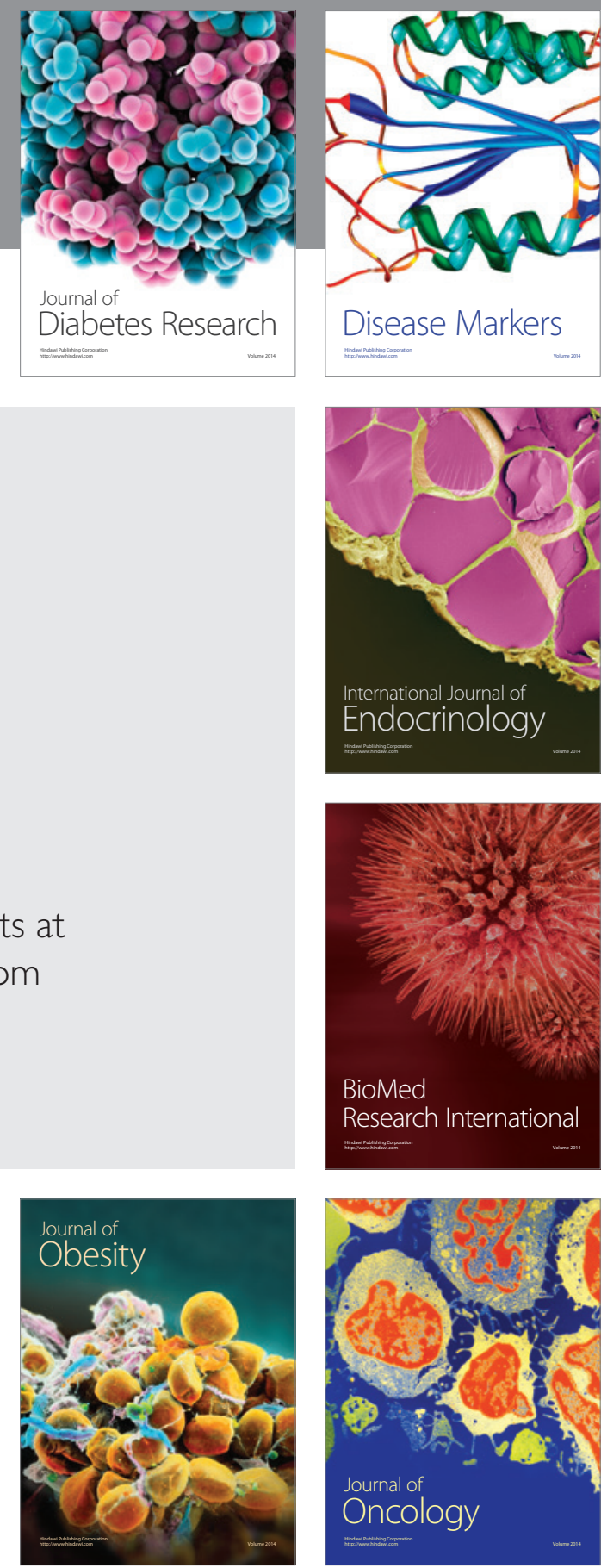

Disease Markers
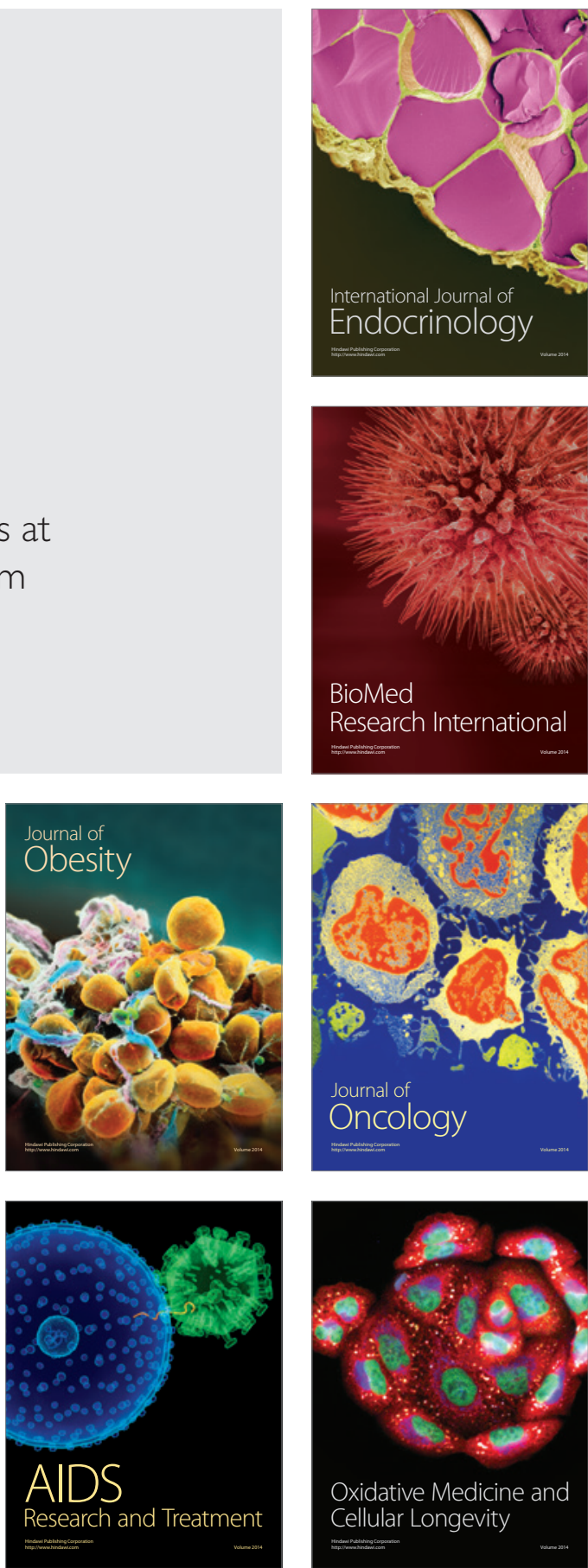